\title{
Brief Report \\ YB-1 Oncoprotein Controls PI3K/Akt Pathway by Reducing Pten Protein Level
}

\author{
Antonella Delicato (D), Eleonora Montuori, Tiziana Angrisano $\mathbb{D}^{\text {, }}$, Alessandra Pollice * and Viola Calabrò *(D) \\ Department of Biology, University of Naples Federico II, MSA-Via Cinthia, 26-80126 Naples, Italy; \\ antonella.delicato@unina.it (A.D.); el.montuori@studenti.unina.it (E.M.); tangrisa@unina.it (T.A.) \\ * Correspondence: apollice@unina.it (A.P.); vcalabro@unina.it (V.C.)
}

Citation: Delicato, A.; Montuori, E.; Angrisano, T.; Pollice, A.; Calabrò, V. YB-1 Oncoprotein Controls PI3K/Akt Pathway by Reducing Pten Protein Level. Genes 2021, 12, 1551. https:// doi.org/10.3390/genes12101551

Academic Editor: Peixin Dong

Received: 21 August 2021

Accepted: 28 September 2021

Published: 29 September 2021

Publisher's Note: MDPI stays neutral with regard to jurisdictional claims in published maps and institutional affiliations.

Copyright: (c) 2021 by the authors. Licensee MDPI, Basel, Switzerland. This article is an open access article distributed under the terms and conditions of the Creative Commons Attribution (CC BY) license (https:/ / creativecommons.org/licenses/by/ $4.0 /)$.

\begin{abstract}
YB-1 is a multifunctional protein overexpressed in many types of cancer. It is a crucial oncoprotein that regulates cancer cell progression and proliferation. Ubiquitously expressed in human cells, YB-1 protein functions are strictly dependent on its subcellular localization. In the cytoplasm, where YB-1 is primarily localized, it regulates mRNA translation and stability. However, in response to stress stimuli and activation of PI3K and RSK signaling, YB-1 moves to the nucleus acting as a prosurvival factor. YB-1 is reported to regulate many cellular signaling pathways in different types of malignancies. Furthermore, several observations also suggest that YB- 1 is a sensor of oxidative stress and DNA damage. Here we show that YB-1 reduces PTEN intracellular levels thus leading to PI3K/Akt pathway activation. Remarkably, PTEN reduction mediated by YB-1 overexpression can be observed in human immortalized keratinocytes and HEK293T cells and cannot be reversed by proteasome inhibition. Real-time PCR data indicate that YB-1 silencing up-regulates the PTEN mRNA level. Collectively, these observations indicate that YB-1 negatively controls PTEN at the transcript level and its overexpression could confer survival and proliferative advantage to PTEN proficient cancer cells.
\end{abstract}

Keywords: YB-1; PTEN; cold-shock proteins; proteasome; PI3K/Akt pathway

\section{Introduction}

YB-1 is a DNA- and RNA-binding protein and transcription factor with an evolutionarily ancient and conserved cold shock domain [1]. In healthy tissues, YB-1 is primarily cytoplasmic, where it plays an important role in regulating various aspects of RNA biology [2]. YB-1 is a major component of translationally inactive messenger ribonucleoprotein particles (mRNPs) and is mainly responsible for the storage of mRNAs in a silent state [3].

Since its initial discovery, the Y-box binding protein 1 (YB-1) was linked to oncogenic functions and chemotherapy resistance. YB-1 is upregulated in tumors and its nuclear localization is associated with a more aggressive phenotype indicating a poor prognosis [4-7]. In response to genotoxic stress, YB-1 translocates from the cytoplasm to the nucleus [8], where it acts as a transcriptional regulator to overcome DNA damage-dependent cell cycle arrest and promote cell survival [9].

YB-1 is a direct target of the serine/threonine kinase Akt. Akt is activated by phosphorylation at Ser473. Overstimulated Akt activity in cancer cells [10] induces YB-1 phosphorylation at Ser102 and nuclear accumulation without changing the total amount of the protein. This results in reduced DNA repair in cancer cells after irradiation [3].

The nuclear accumulation of YB-1 in response to DNA damage or transcription inhibition requires a decrease in the cytoplasmic mRNA level [11]. Indeed, like Akt, YB-1 is associated with inactive mRNPs and, activated Akt relieves translational repression of the YB-1-bound mRNAs thereby facilitating translational activation of silenced mRNA species [3,12].

The main negative regulator of the PI3K-Akt pathway remains the PTEN phosphatase. Phosphatase and tensin homolog deleted on chromosome 10 (PTEN) is recognized as a tu- 
mor suppressor due to its negative regulation of the phosphatidylinositol-4, 5-bisphosphate 3-kinase (PI3K)/protein kinase B (Akt) signaling pathway [13], see Figure 1. The major target of PTEN is phosphatidylinositol $(3,4,5)$-triphosphate (PIP3), which is generated by PI3K and acts as a bridge to recruit 3-phosphoinositide-dependent protein kinase 1 (PDK1) and AKT to the plasma membrane, further activating AKT by phosphorylation at its T308 site $[13,14]$. PTEN converts PIP3 into PIP2, interrupting the interaction between PDK1 and AKT, and thus negatively mediating the activation of AKT. Apart from its membrane-bound form, nuclear PTEN has multiple functions, including the induction of cell cycle arrest by inhibiting cyclin D1 expression [15], maintenance of chromosomal stability, and DNA double-strand break repair [16].

Loss of PTEN activity has been identified in a wide spectrum of primary and metastatic neoplasms, including breast cancer [17]. This condition, which results in low or null expression of the protein, is believed to be an early oncogenic event in several tumor types $[18,19]$. Given the ability of Akt to physically interact and activate YB-1 oncogenic functions [3] we hypothesize that YB-1 was, in turn, able to regulate Akt by a positive control that could mirror what happens in vivo when YB-1 overexpression sustains the proliferative and survival potential of cancer cells. Very little information about YB-1 and PTEN functional crosstalk is now available. However, a significant association of YB-1 nuclear accumulation with PTEN deletion in advanced prostate tumor stages was reported by Heumann and collaborators in 2017 thus suggesting a possible reciprocal regulation between the two proteins of the PI3K/Akt pathway [20]. Here we provide compelling evidence that YB-1 can sustain Akt activation by controlling PTEN.

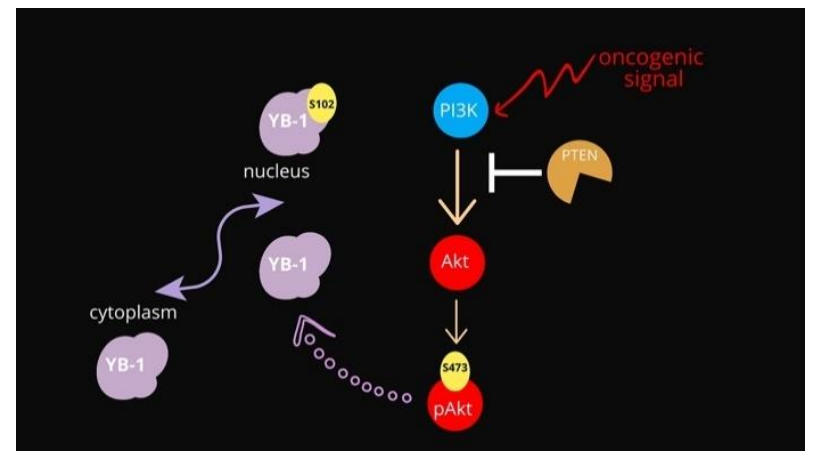

Figure 1. Schematic representation of the PI3K/Akt pathway overseeing YB-1 activation.

\section{Materials and Methods}

\subsection{Plasmids and Reagents}

The expression plasmid 3XFlag-YB-1 wt was used for the transfection and provided by Dr. Arezoo Astanehe (Abbotsford, BC, Canada). The pcDNA-GFP plasmid, used as a control, was purchased by Thermo-Fisher Scientific (Waltham, MA, USA). Sodium (meta)arsenite $\left(\mathrm{NaAsO}_{2}, \mathrm{S7400}\right.$, Sigma-Aldrich, St. Louis, MO, USA) and copper (II) sulfate (C1297, Sigma-Aldrich) were used to treat cell culture at $300 \mu \mathrm{M}$ and $10 \mu \mathrm{M}$ final concentrations, respectively. MG-132 (M8699, Sigma-Aldrich) was used as a proteasome inhibitor at $10 \mu \mathrm{M}$ final concentration, for $4 \mathrm{~h}$.

\subsection{Cell Cultures}

Human embryonic kidney cells (HEK293T) and HaCaT (human spontaneously immortalized keratinocytes from adult skin) were purchased from Cell Line Service (CLS, Germany) and cultured in a humidified incubator at $37^{\circ} \mathrm{C}$ and $5 \% \mathrm{CO} 2$ in DMEM High glucose (Gibco BRL, Grand Island, NY, USA) supplemented with 10\% Fetal Bovine Serum (Gibco BRL), 1\% L-glutamine (Gibco BRL) and 1\% Pen-Strep solution (Gibco BRL). Cells were routinely checked for mycoplasma contamination, using a mycoplasma detection kit (Abcam, Quebec, QC, Canada). 
To increase HEK293T adhesion to glass/plastic surfaces, plates were treated with poly-D-lysine $(0.1 \mathrm{mg} / \mathrm{mL}$, P7405, Sigma-Aldrich) before seeding cells.

\subsection{Immunoblotting Analysis}

For total protein extraction $2.5 \times 10^{5}$ cells were seeded in 6-well. After $48 \mathrm{~h}$, cells were harvested in lysis buffer ( $50 \mathrm{mM}$ Tris- $\mathrm{HCl} \mathrm{pH}$ 7.5, $5 \mathrm{mM}$ EDTA, $150 \mathrm{mM} \mathrm{NaCl}, 1 \% \mathrm{NP}-40$, $0.5 \%$ sodium deoxycholate) with the addition of $1 \mathrm{mM}$ phenylmethylsulfonyl fluoride and protease and phosphatase inhibitor cocktail (Sigma-Aldrich). Cells were detached with a scraper and left on ice for $30^{\prime}$. Then extracts were clarified by centrifugation at $13,200 \mathrm{rpm}$ for $30^{\prime}$ at $4^{\circ} \mathrm{C}$. The amount of protein in the samples was determined by the Bio-Rad protein assay (Bio-Rad, Milan, Italy).

After the addition of Laemmli buffer (Sigma-Aldrich) samples were boiled at $100^{\circ} \mathrm{C}$ for $5 \mathrm{~min}$ and resolved by SDS- polyacrylamide gel electrophoresis (SDS-PAGE). About $20 \mu \mathrm{g}$ of total extracts were separated by SDS-PAGE.

Proteins were then transferred to a polyvinylidene difluoride membrane (PVDF, Millipore) using a Mini trans-blot apparatus (Bio-Rad) according to the manufacturer's instructions. The PVDF membrane was blocked in 5\% $w / v$ milk buffer $(5 \% w / v$ non-fat dried milk, $50 \mathrm{mM}$ Tris, $200 \mathrm{mM} \mathrm{NaCl}, 0.2 \%$ Tween 20) and incubated overnight at $4{ }^{\circ} \mathrm{C}$ with primary antibodies diluted in $5 \% w / v$ milk or bovine serum albumin (BSA) buffer according to the manufacturer's instructions. Following three washes with TBST (Tris-buffered saline, $0.1 \%$ Tween), the blots were incubated for 1 hour at RT with HRP-conjugated secondary antibodies (Sigma-Aldrich). Proteins were visualized by enhanced chemiluminescence (ECL, Bio-Rad) and analyzed by Quantity One W software of ChemiDoc TM XRS system (Bio-Rad).

Band intensities were quantified by ImageJ Software (http://imageJ.nih.gov/ij/, accessed on 21 August 2021, free software, downloaded from the NIH, Bethesda, MD, USA), normalized respect loading control and reported as fold enrichment to the control sample.

\subsection{Antibodies}

The primary antibodies used are: anti-YB-1 raised against the region 1 to 100 of YB-1 protein (12148 Abcam, Cambridge, UK); anti-Actin (8432 Santa Cruz, Dallas, TX, USA); anti-PTEN (Cell Signaling, Danvers, MA, USA, 9559S); anti-Phospho-Akt (Ser473) (193H12) (Cell Signaling, 4058S); anti-Akt (Cell Signaling, 2920S).

\subsection{Transfections and RNA Interference}

Cells were transfected using Lipofectamine 2000 (Life Technologies, Carlsbad, CA, USA) according to the manufacturer's recommendations. Briefly, cells were seeded at $70-80 \%$ confluence $\left(2.5 \times 10^{5}\right)$ in 6-well and transiently transfected with plasmids at a concentration of $300 \mathrm{ng}$ for $48 \mathrm{~h}$. MG-132 was added to the cells at the concentration of $10 \mu \mathrm{M} 4 \mathrm{~h}$ before the end of transfection.

YB-1 transient silencing was carried out with IBONI YB-1 small interfering (siRNA) pool (RIBOXX GmbH, Radebeul, Germany) as a pool of 3 different siRNAs and RNAiMAX reagent (Life Technologies), according to the manufacturer's recommendations. Cells were seeded at $70-80 \%$ confluence $\left(2.5 \times 10^{5}\right)$ in 6-well and transiently silenced with IBONI YB1-siRNA at $150 \mathrm{nM}$ final concentration.

Negative Control siRNA, provided by RIBOXX (Germany) was used as a negative control.

YB-1 guide and passenger sequences:

$h$ YBX-1 guide $\left(5^{\prime}-3^{\prime}\right)$ :

UUUAUCUUCUUCAUUGCCGCCCCC

UUAUUCUUCUUUAUGGCAGCCCCC

UAUUUGAUGACCACACCAGCCCCC

$h$ YBX-1 passenger $\left(5^{\prime}-3^{\prime}\right)$ : 
GGGGGCGGCAAUGAAGAAGAUAAA

GGGGGCUGCCAUAAAGAAGAAUAA

GGGGGCUGGUGUGGUCAUCAAAUA

\subsection{Co-Immunoprecipitation}

For co-immunoprecipitations (Co-IP) $2 \times 10^{6}$ HEK293T cells were seeded in poly-Dlysine pre-treated 100-mm dishes; the day after Dynabeads Protein A (Invitrogen) were incubated with antibodies against $\mathrm{YB}-1,3 \mu \mathrm{g}$ for $1.5 \mathrm{mg}$ of protein extract for $10^{\prime}$ at room temperature in rotation after protein extract was incubated with the Dynabeads-Ab complex overnight at $4{ }^{\circ} \mathrm{C}$. Immunoglobulin $\mathrm{G}(\mathrm{IgG}) 3 \mu \mathrm{g}$ for $1.5 \mathrm{mg}$ of protein extract was used as a negative control. Immunocomplexes were resolved with SDS-PAGE; immunoblot was performed with anti-PTEN antibody and anti-YB1 antibody.

\subsection{Quantitative Real Time-PCR}

Total RNA was extracted with Trizol reagent (Gibco) according to the manufacturer's instructions. Reverse transcription was performed using All-In-One 5X RT MasterMix (Abcam). AriaMx Real-Time PCR System (Agilent Technologies, Santa Clara, CA, USA) and Brilliant HRM Ultrafast Starter Pack were used. Quantitative relative expression was calculated according to the $2^{-\Delta \Delta C T}$ method (Delta CT method) normalizing to $r p l 0 \mathrm{mRNA}$ expression. Sequences of primers used:

PTEN For: CTCAGCCGTTACCTGTGTGT

PTEN Rev: AGGTTTCCTCTGGTCCTGGT

YB-1 For: CGACCAGACTCTCATCCTGC

YB-1 Rev: TTTGATGACCACACCAGGCA

RPL0 For: GACGGATTACACCTTCCCACTT

RPL0 Rev: GGCAGATGGATCAGCCAAGA

\subsection{Statistical Analysis}

Statistical analyses were performed using GraphPad Prism (version 8.1.2, GraphPad Software Inc., San Diego, CA, USA). Data were presented as the mean \pm standard deviation and analyzed for statistical significance using one-way or two-way analysis of variance (ANOVA) and multiple comparisons. For all tests, $p<0.05$ was considered to indicate a statistically significant difference. To report $p$-values, the New England Journal of Medicine (NEJM) decimal format was used; differences were considered statistically significant at ${ }^{*} p<0.033,{ }^{* *} p<0.002$ and ${ }^{* *} p<0.001$.

\section{Results}

Firstly, we wondered whether there was a direct functional relationship between YB-1 and PTEN. We hypothesized that YB-1 could control PTEN protein level. To address this point, we decided to analyze the effect of YB-1 downregulation on PTEN protein intracellular level.

To this aim, we used PTEN proficient immortalized HaCaT and HEK293T cells, showing robust expression of endogenous YB-1 resembling actively proliferating premalignant cells. YB-1 expression was depleted by RNAi and PTEN levels were checked by immunoblot. Control (siRNA NC) and YB-1 depleted cells (siPool YB-1) were collected $48 \mathrm{~h}$ after transfection and analysed by immunoblot. As shown in Figure 2A we observed a clear increase of PTEN levels in YB-1 depleted HaCaT cells compared to the control with a concomitant reduction of $\mathrm{pAkt}^{\mathrm{S} 743}$ (Figure 2B) in line with a potential role of $\mathrm{YB}-1$ in enhancing Akt phosphorylation at S743 by directly impinging on PTEN/PI3K pathway. An even more evident increase of PTEN protein levels was observed in HEK293T cells upon YB-1 depletion (Figure 2B). Interestingly, an increase of PTEN protein level was also observed in total extracts from HaCaT and HEK293T cells whose level of YB-1 was reduced by oxidative stress stimuli such as that with $\mathrm{NaArs}$ and $\mathrm{Cu}++$ treatments (Figure 2C), as we have previously shown [21]. 

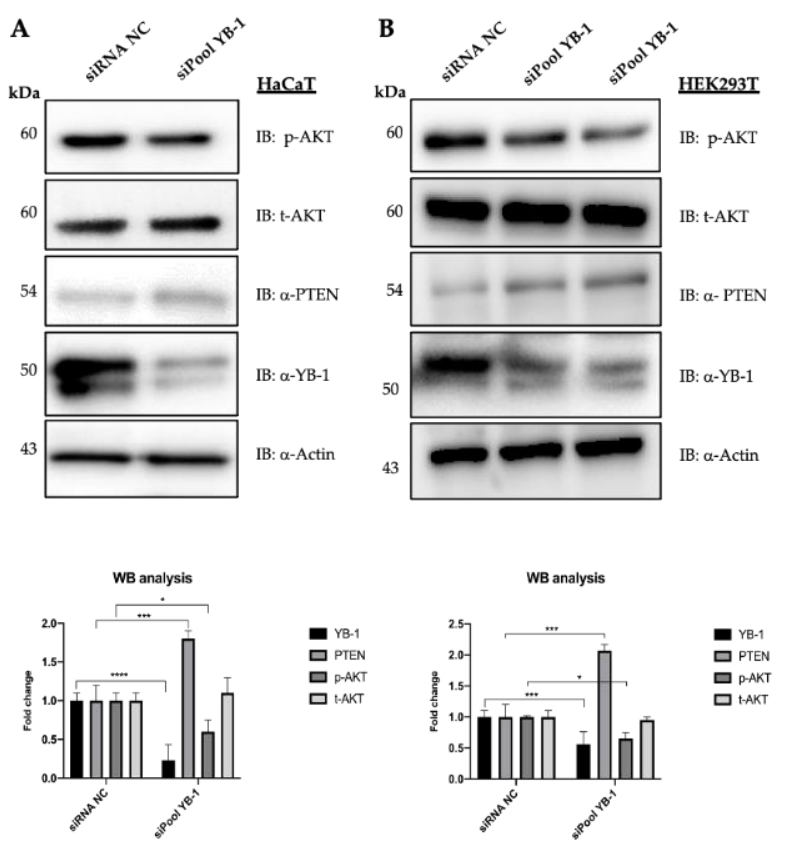

C
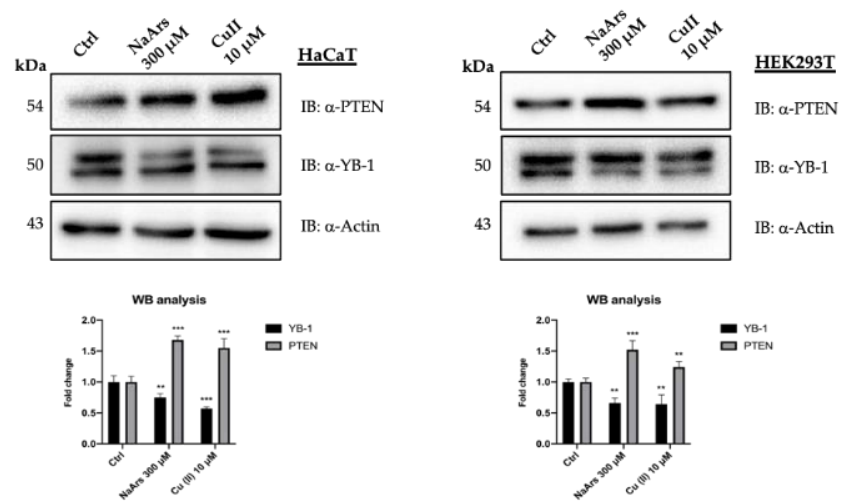

Figure 2. YB-1 controls PTEN levels in HaCaT and HEK293T cells. (A) HaCaT cells were transfected with $10 \mathrm{nM}$ final siRNApoolYB-1 or siRNA-Negative Control (NC). The effect on PTEN intracellular levels was evaluated $48 \mathrm{~h}$ post-transfection by western blot on whole protein lysates probed with anti-PTEN antibodies. Immunoblots were also probed with antibodies against YB-1, pAkt ${ }^{\text {S743 }}$, tAKT and actin as a loading control. (B) HEK293T cells were transfected with 10 nM final siRNA-NC or siRNA-poolYB-1 (duplicated). Whole protein lysates were collected and analysed $48 \mathrm{~h}$ after transfection as described in (A); (C) HaCaT and HEK293T cells were treated with NaArs and Cu (II) for $2 \mathrm{~h}$ to induce oxidative stress. Cell lysates were analyzed by immunoblot with antibodies against PTEN, YB1 and actin used as a loading control. For comparison, siRNA-transfected extracts were used. Statistical analyses were performed using 2-way ANOVA and Sidak's multiple comparison or Dunnett's multiple comparisons test. Levels of significance between points of expression are indicated $\left(* * * 00.001,{ }^{* *} p<0.01, * p<0.05\right)$.

We then decided to look next at the effect of YB-1 overexpression on PTEN protein levels. To this aim, we transfected YB1 expression vector in HEK293T or HaCat cells treated or not with the proteasome inhibitor MG132. At $48 \mathrm{~h}$ after transfection, cells were collected, and the extracts were analysed by immunoblot. As shown in Figure 3A we observed a moderate but significant reduction of PTEN protein level, compared to the control, that was not rescued by MG132 treatment thus suggesting that it does not occur through a proteasome-dependent mechanism. We also tested for a possible interaction between YB-1 and PTEN proteins by co-immunoprecipitation. However, as shown in Figure 3B, YB-1 antibodies were unable to immunoprecipitate endogenous PTEN.

Given the importance of YB-1 function in the control of RNA metabolism, we wished to explore whether YB-1 depletion was able to alter the level of PTEN mRNA. Therefore, we depleted HaCaT and HEK293T cells of YB-1 using the siRNA pool against YB-1 (siPoolYB-1) [21]. Total RNA was extracted and subjected to RT-qPCR. As shown in Figure 4, compared to the control sample the mRNA level of YB-1 was reduced to 0.25 in HaCaT and 0.40 in HEK293T cells while PTEN mRNA was increased to 1.75 in HaCaT and 1.5 in HEK293T cells. 
A
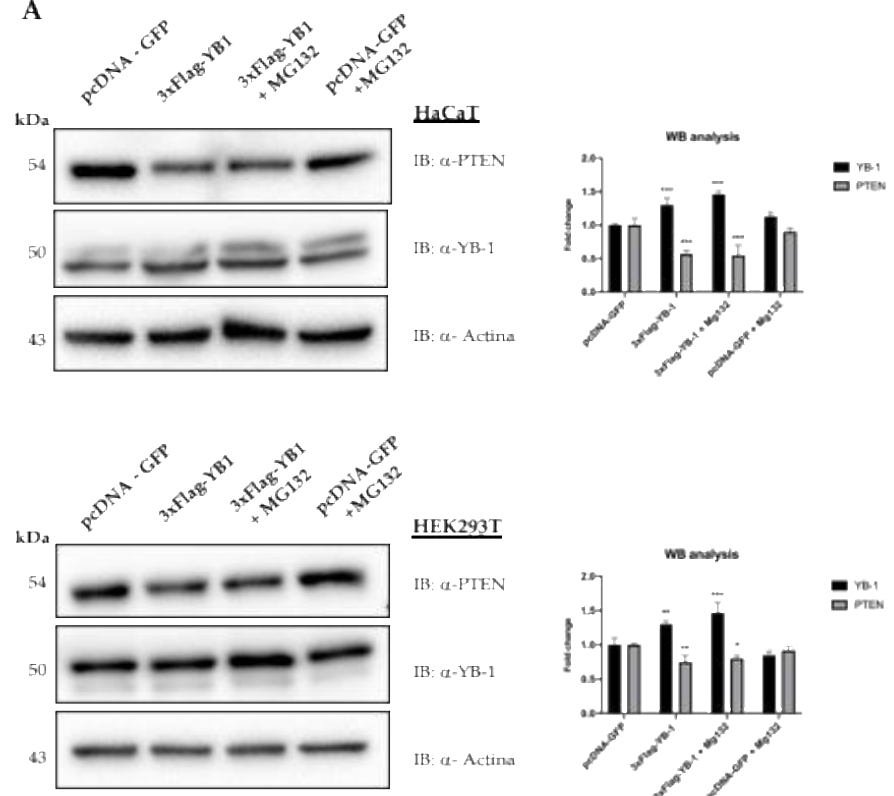

B

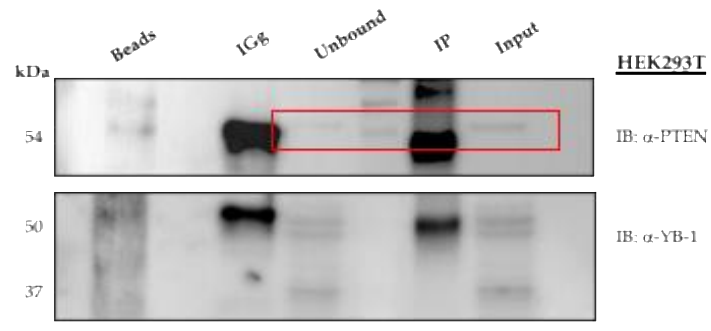

Figure 3. YB-1 mediated reduction of PTEN levels requires neither the proteasomal activity nor the physical interaction between the two proteins. (A) HaCaT cells (top panel) and HEK293T cells (lower panel) were transfected with 3XFlag-YB-1 plasmid or pcDNA-GFP as a control. Effect on PTEN intracellular levels was evaluated $48 \mathrm{~h}$ post-transfection by western blot on whole protein lysates probed with anti-YB-1, anti-PTEN, and anti-actin as a loading control. $10 \mu \mathrm{M} \mathrm{MG132} \mathrm{for} 4 \mathrm{~h}$ before the end of transfection was used to inhibit proteasome activity. (B) HEK293T protein extracts were immunoprecipitated with anti-YB-1 antibodies. Immunocomplexes were subjected to western blot and revealed using antibodies against PTEN. PTEN signal in unbound and input are highlighted in the rectangle box. Statistical analysis was performed using 2-way ANOVA and Sidak's multiple comparison test. Levels of significance between points of expression are indicated $\left({ }^{* * *} p<0.001\right.$, ** $p<0.01, * p<0.05)$.
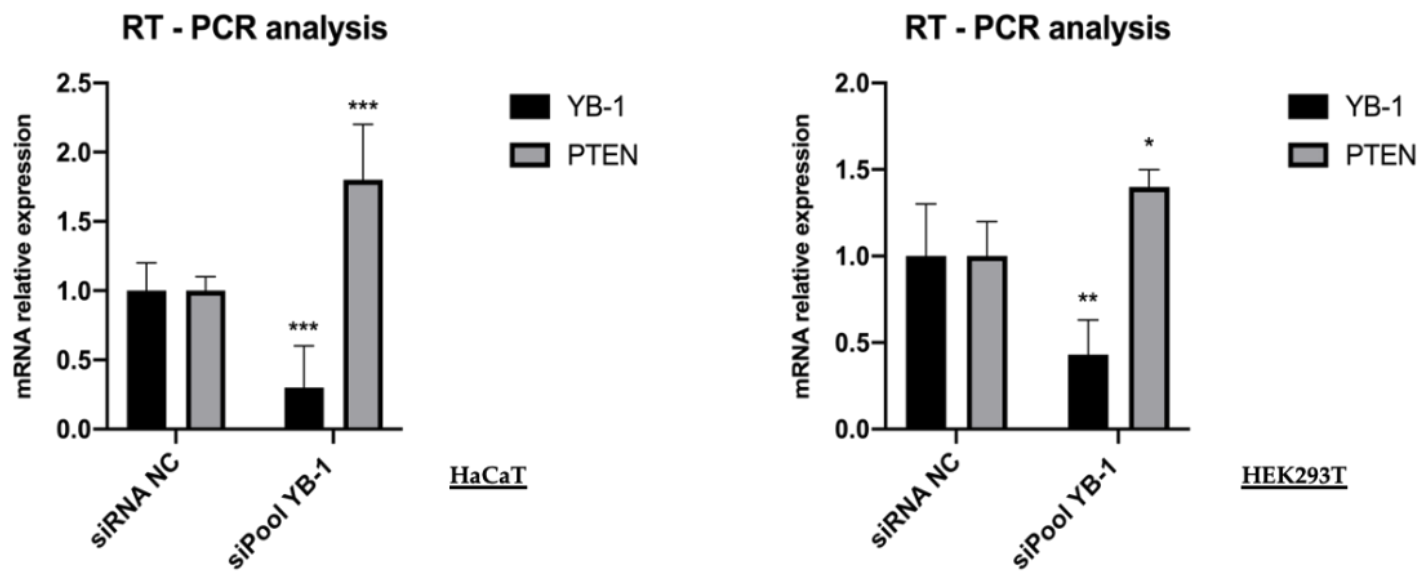

Figure 4. YB-1 depletion increases the level of PTEN transcript. HaCaT and HEK293T cells were transfected with 10 nM final siRNA-poolYB-1 or siNC; the effect on PTEN mRNA level was evaluated 48h post-transfection by qRT-PCR analysis. Relative mRNA levels were plotted on the y-axis and siRNA employed are indicated on the x-axis. RPL0 ribosomal protein mRNA was used for normalization. Statistical analyses were performed using 2-way ANOVA and Sidak's multiple comparison test. Levels of significance between points of expression are indicated $\left({ }^{* *} p<0.001,{ }^{* *} p<0.01,{ }^{*} p<0.05\right)$.

This result showed that the effect of YB-1 on PTEN was primarily at mRNA level. It is important to remind that PTEN functions in a dosage-dependent manner during tumor development and that moderate PTEN reduction, without complete loss, has been reported to activate the PI3K/Akt pathway and to be associated with chemoresistance and cancer progression $[22,23]$. 


\section{Conclusions}

The data presented here show evidence that YB-1 controls PTEN protein levels by acting at the transcript level. Our data are in line with what is already known regarding the function of both proteins, although a direct functional link between PTEN and YB-1 has never been assessed. At the functional level increased expression of YB-1 can restrain PTEN expression thus enforcing Akt activation in premalignant cells (Figure 5). Akt, in turn, increases the pro-proliferative and pro-survival activities of YB-1 by inducing YB1 phosphorylation at S102 thereby promoting its nuclear translocation.

The PTEN level appears to be tightly controlled both transcriptionally and posttranscriptionally [24]. Some oncogenic microRNA and ncRNAs have been found to target PTEN mRNA and regulate malignant progression [25], ncRNAs including lncRNAs and miRNAs act alone or interact with each other to regulate PTEN expression and it has recently been proposed that some of the oncogenic effects of YB- 1 in breast cancer may be mediated through its interactions with sncRNAs [26].

Although the precise mechanism through which YB-1 controls PTEN mRNA level remains to be determined, our data suggest the existence of a positive feedback loop between YB-1 and Akt, reinforcing each other, probably occurring at an early step in cancer progression and conferring a selective advantage to premalignant cells. Elucidation of the details about how YB-1 downregulates PTEN expression may provide novel insights into the regulation network of PTEN, which could suggest possible anticancer strategies focusing on targeting both YB-1 and the PI3K/Akt pathway.

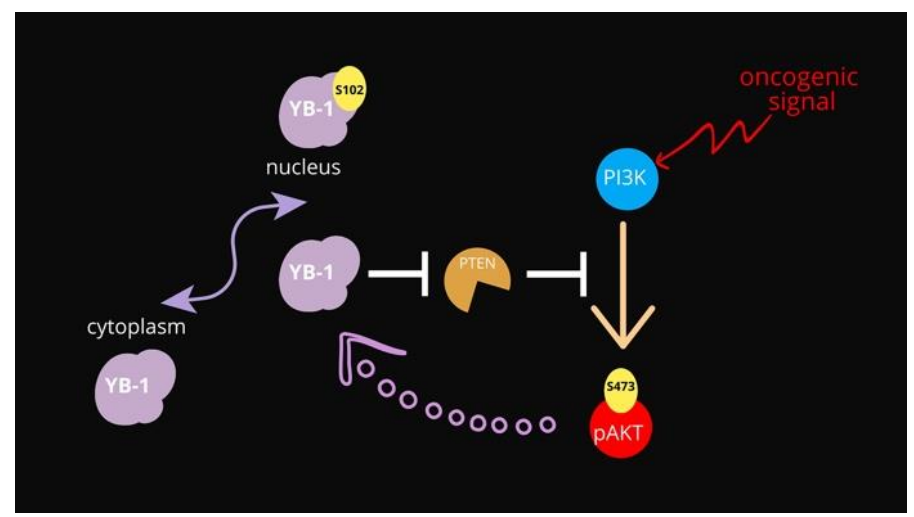

Figure 5. Schematic representation of the proposed functional relationships among YB-1, PTEN and Akt. In normal conditions, YB-1 is mainly cytoplasmic. The Akt-dependent phosphorylation of YB-1 at $\mathrm{S} 102$ promotes its translocation to the nuclear compartment promoting cell survival.

Author Contributions: Conceptualization: V.C.; Methodology and investigation: A.D. and E.M.; data curation: A.D.; writing of the original draft preparation: V.C.; supervision, A.P., T.A. and V.C.; project administration and funding acquisition: A.P., V.C., T.A. All authors have read and agreed to the published version of the manuscript.

Funding: This research received funds from University Federico II of Naples, "Ricerca Dipartimentale 000020-PRD2020".

Institutional Review Board Statement: Not applicable.

Informed Consent Statement: Not applicable.

Conflicts of Interest: The authors declare no conflict of interest. The funders had no role in the design of the study; in the collection, analyses, or interpretation of data; in the writing of the manuscript, or in the decision to publish the results. 


\section{References}

1. Lindquist, J.A.; Mertens, P.R. Cold shock proteins: From cellular mechanisms to pathophysiology and disease. Cell Commun. Signal. 2018, 16, 11-14. [CrossRef]

2. Metha, S.; McKinney, C.; Algie, M.; Verma, C.S.; Kannan, S.; Harfoot, R.; Bartolec, T.K.; Bhatia, P.; Fisher, A.J.; Gould, M.L.; et al. Dephosphorylation of yb-1 is required for nuclear localisation during G2 phase of the cell cycle. Cancers 2020, 12, 2-315.

3. Evdokimova, V.; Ruzanov, P.; Anglesio, M.S.; Sorokin, A.S.; Ovchinnikov, L.P.; Buckley, J.; Triche, T.J.; Sonenberg, N.; Sorensen, P.H.B. Akt-mediated YB-1 phosphorylation activates translation of silent mRNA species. Mol. Cell. Biol. 2006, 26, 277-292. [CrossRef]

4. Fujii, T.; Yokoyama, G.; Takahashi, H.; Namoto, R.; Nakagawa, S.; Toh, U.; Kage, M.; Shirouzu, K.; Kuwano, M. Preclinical studies of molecular-targeting diagnostic and therapeutic strategies against breast cancer. Breast Cancer 2008, 15, 73-78. [CrossRef] [PubMed]

5. Kuwano, M.; Oda, Y.; Izumi, H.; Yang, S.J.; Uchiumi, T.; Iwamoto, Y.; Toi, M.; Fujii, T.; Yamana, H.; Kinoshita, H.; et al. The role of nuclear Y-box binding protein 1 as a global marker in drug resistance. Mol. Cancer Ther. 2004, 3, 1485-1492. [PubMed]

6. Kashihara, M.; Azuma, K.; Kawahara, A.; Basaki, Y.; Hattori, S.; Yanagawa, T.; Terazaki, Y.; Takamori, S.; Shirouzu, K.; Aizawa, H.; et al. Nuclear Y-box binding protein-1, a predictive marker of prognosis, is correlated with expression of HER2/ErbB2 and HER3/ErbB3 in non-small cell lung cancer. J. Thorac. Oncol. 2009, 4, 1066-1074. [CrossRef] [PubMed]

7. Hohlfeld, R.; Brandt, S.; Bernhardt, A.; Gorny, X.; Schindele, D.; Jandrig, B.; Schostak, M.; Isermann, B.; Lindquist, J.A.; Mertens, P.R. Crosstalk between Akt signaling and cold shock proteins in mediating invasive cell phenotypes. Oncotarget $2018,9,19039$. [CrossRef] [PubMed]

8. Cohen, S.B.; Ma, W.; Valova, V.A.; Algie, M.; Harfoot, R.; Woolley, A.G.; Robinson, P.J.; Braithwaite, A.W. Genotoxic stress-induced nuclear localization of oncoprotein YB-1 in the absence of proteolytic processing. Oncogene 2010, 29, 403-410. [CrossRef]

9. Eliseeva, I.A.; Kim, E.R.; Guryanov, S.G.; Ovchinnikov, L.P.; Lyabin, D.N. Y-box-binding protein 1 (YB-1) and its functions. Biochemistry 2011, 76, 1402-1433. [CrossRef]

10. Lettau, K.; Zips, D.; Toulany, M. Simultaneous targeting of rsk and akt efficiently inhibits yb-1-mediated repair of ionizing radiation-induced DNA double-strand breaks in breast cancer cells. Int. J. Radiat. Oncol. Biol. Phys. 2021, 109, 567-580. [CrossRef]

11. Kretov, D.A.; Mordovkina, D.A.; Eliseeva, I.A.; Lyabin, D.N.; Polyakov, D.N.; Joshi, V.; Desforges, B.; Hamon, L.; Lavrik, O.I.; Pastré, D.; et al. Inhibition of transcription induces phosphorylation of YB-1 at Ser102 and its accumulation in the nucleus. Cells 2020, 9, 104. [CrossRef]

12. Kuwano, M.; Shibata, T.; Watari, K.; Ono, M. Oncogenic Y-box binding protein-1 as an effective therapeutic target in drug-resistant cancer. Cancer Sci. 2019, 110, 1536-1543. [CrossRef] [PubMed]

13. Maehama, T.; Dixon, J.E. The tumor suppressor, PTEN/MMAC1, dephosphorylates the lipid second messenger, phosphatidylinositol 3, 4, 5-trisphosphate. J. Biol. Chem. 1998, 273, 13375-13378. [CrossRef] [PubMed]

14. Richman, S. Deficient mismatch repair: Read all about it. Int. J. Oncol. 2015, 47, 1189-1202. [CrossRef] [PubMed]

15. Radu, A.; Neubauer, V.; Akagi, T.; Hanafusa, H.; Georgescu, M.M. PTEN induces cell cycle arrest by decreasing the level and nuclear localization of cyclin D1. Mol. Cell. Biol. 2003, 23, 6139-6149. [CrossRef] [PubMed]

16. Ming, M.; He, Y.Y. PTEN in DNA damage repair. Cancer Lett. 2012, 319, 125-129. [CrossRef]

17. Carbognin, L.; Miglietta, F.; Paris, I.; Dieci, M.V. Prognostic and predictive implications of PTEN in breast cancer: Unfulfilled promises but intriguing perspectives. Cancers 2019, 11, 1401. [CrossRef] [PubMed]

18. Milella, M.; Falcone, I.; Conciatori, F.; Cesta Incani, U.; Del Curatolo, A.; Inzerilli, N.; Nuzzo, C.M.; Vaccaro, V.; Vari, S.; Cognetti, F.; et al. PTEN: Multiple functions in human malignant tumors. Front. Oncol. 2015, 5, 24. [CrossRef]

19. Lee, Y.R.; Chen, M.; Pandolfi, P.P. The functions and regulation of the PTEN tumour suppressor: New modes and prospects. Nat. Rev. Mol. Cell Biol. 2018, 19, 547-562. [CrossRef]

20. Heumann, A.; Kaya, Ö.; Burdelski, C.; Hube-Magg, C.; Kluth, M.; Lang, D.S.; Simon, R.; Beyer, B.; Thederan, I.; Sauter, G.; et al. Up regulation and nuclear translocation of Y-box binding protein 1 (YB-1) is linked to poor prognosis in ERG-negative prostate cancer. Sci. Rep. 2017, 17, 2056. [CrossRef]

21. Guarino, A.M.; Troiano, A.; Pizzo, E.; Bosso, A.; Vivo, M.; Pinto, G.; Amoresano, A.; Pollice, A.; La Mantia, G.; Calabrò, V. Oxidative stress causes enhanced secretion of YB-1 protein that restrains proliferation of receiving cells. Genes $2018,9,513$. [CrossRef]

22. Alimonti, A.; Carracedo, A.; Clohessy, J.G.; Trotman, L.C.; Nardella, C.; Egia, A.; Salmena, L.; Sampieri, K.; Haveman, W.J.; Brogi, E.; et al. Subtle variations in Pten dose determine cancer susceptibility. Nat. Genet. 2010, 42, 454-458. [CrossRef]

23. Rich, J.N. Cancer stem cells in radiation resistance. Cancer Res. 2007, 67, 8980-8984. [CrossRef]

24. Leslie, N.R.; Foti, M. Non-genomic loss of PTEN function in cancer: Not in my genes. Trends Pharmacol. Sci. 2011, 32, 131-140. [CrossRef]

25. Mouw, J.K.; Yui, Y.; Damiano, L.; Bainer, R.O.; Lakins, J.N.; Acerbi, I.; Ou, G.; Wijekoon, A.C.; Levental, K.R.; Gilbert, P.M.; et al. Tissue mechanics modulate microRNA-dependent PTEN expression to regulate malignant progression. Nat. Med. 2014, 20, 360-367. [CrossRef] [PubMed]

26. Blenkiron, C.; Hurley, D.G.; Fitzgerald, S.; Print, C.G.; Lasham, A. Links between the oncoprotein YB-1 and small non-coding RNAs in breast cancer. PLoS ONE 2013,8, e80171. [CrossRef] [PubMed] 